\title{
LA ENTREVISTA DE PRENSA. CONSIDERACIÓN PRÁCTICA Y CONCEPTUAL DE UN GÉNERO INFORMATIVO ESENCIAL.
}

\author{
Juan Francisco Torregrosa Carmona -
}

Universidad Complutense. Departamento de Periodismo II, Madrid, España.

\section{Resumen}

El presente trabajo se acerca al mundo del periodismo impreso a partir de un género informativo esencial como es la entrevista, modalidad propia de presentación textual, además de base de otros géneros como el reportaje y, en su caso, la crónica, entre algunos posibles más.

Se hace un repaso sobre su papel en el trabajo diario del periodista, además de una aproximación conceptual al género. En este sentido, se abordan los principales tipos de entrevista que suelen ofrecer tanto los periódicos diarios como la prensa semanal, para lo cual se tiene en cuenta la bibiografía más destacada sobre la materia.

Tanto la entrevista en su fórmula más convencional como otras variantes son tenidas en cuenta para valorar el papel que desempeñan esta clase de textos informativos e informativo-interpretativos en la narración de la actualidad informativa. Una narración que debería apoyarse en la separación clara entre información y opinión, ámbito este último para el que están precisamente reservados unos géneros específicos. De hecho, la mejor tradición periodística anglosajona, la de mayor calidad, siempre ha reivindicado la observación de esa separación, y la fidelidad a la información factual, como un elemento necesario incluso en el aspecto deontológico, a partir de la siguiente sentencia clásica: "Los hechos son sagrados, las opiniones son libres".

\section{Palabras clave}

Entrevista, prensa, periodismo, géneros, información.

\section{La entrevista como herramienta de trabajo del periodista}

La entrevista periodística constituye una herramienta vital para el trabajo del periodista. Puede constituir un género informativo e interpretativo autónomo o ser la base para el tratamiento de la información obtenida mediante otras fórmulas, como el reportaje. En concreto, existe una modalidad que parte de la entrevista para adoptar finalmente la forma literaria del reportaje: lo que algunos autores han 
denominado "reportaje de citas", para diferenciarlo tanto de la entrevista convencional que emplea la estructura de pregunta-respuesta, como de otros tipos de reportajes en profundidad en los que las declaraciones de los protagonistas de la actualidad ocupan un lugar secundario a favor de la propia escritura del reportero o redactor de calle.

Los objetivos de una entrevista pueden variar en alguna medida en función de los tipos de entrevista que trataremos a continuación, pero siempre existirá una base común: el acercamiento a la obra o actividad de un personaje, generalmente público, y en menor medida a su propia vida. El éxito de una entrevista dependerá de factores múltiples, entre ellos, quién sea el entrevistado, si bien existen aspectos de cuya adecuada ocupación por parte del entrevistador dependerá la mayor parte de la eficacia o el fracaso del resultado, hasta el punto de que podría ponerse en peligro la publicación de una entrevista que no estuviera a la altura de un medio de prestigio.

Para evitar ese riesgo, o incluso su materialización, se debe tener en cuenta que hay pocas posibilidades de realizar una entrevista brillante sin una previa labor de investigación y planificación documental. En efecto, el periodista tiene la obligación de localizar y consultar fuentes y documentación de suficiente calidad y fiabilidad para poder conocer al personaje y en consecuencia realizar preguntas fundamentadas y con el adecuado rigor y nivel de profundidad. Con frecuencia, la labor de documentación consiste exclusivamente en el conocimiento de otras entrevistas publicadas por los medios, propios o ajenos, a la personalidad en cuestión. Eso, con ser necesario, no resulta suficiente: entre otras cosas, porque hay ocasiones en que se publican errores o datos incorrectos en la transcripción de las respuestas que se podrían reproducir, lo que afectaría negativamente a la labor del informador, al poner de manifiesto su precaria actividad de documentación. Por tanto, hay que ir más allá, intentando contactar con fuentes personales, consultando archivos y bases de datos, acudiendo a otras instancias documentales, etcétera. En definitiva, dando cumplimiento a las principales funciones de la documentación informativa o periodística.

Junto con la labor de documentación considerada, y junto con otros factores como la imaginación a la hora de preguntar, el rigor, la precisión lingüística, gramatical, semántica..., se deben tener en cuenta toda una serie de aspectos prácticos que hay que cuidar tanto antes de la entrevista como durante su realización e incluso después. En este sentido, los más experimentados entrevistadores de prensa insisten en la necesidad de que el entrevistado se sienta cómodo, puesto que si no es así, difícilmente obtendremos información valiosa o novedosa. La actitud del periodista debe ir en esa dirección, lo que no equivale a una complacencia por su parte excesiva o injustificada.

Entre las cuestiones que el entrevistador no puede olvidar mientras hace la entrevista está el hecho de que el cuestionario que debe tener preparado 
(físicamente -lo ideal- o en su mente, si cuenta con gran experiencia y capacidad suficiente para ello) nunca debe encontrarse totalmente cerrado: es decir, las respuestas del interpelado pueden y a veces deben dar lugar a preguntas que no estaban previstas, o a una reformulación de algunas que se pensaba realizar de otra manera. Por tanto, toda entrevista es un acto de comunicación de naturaleza conversacional, en la que el diálogo no puede estar acotado en exceso antes de empezar. Antes al contrario, si como ocurre en radio o en televisión la mejor improvisación nace siempre de un buen guión, habrá que tener en cuenta que todo lo que hayamos preparado es susceptible de ser cambiado en mayor o menor medida sobre la marcha en función de las necesidades concretas del momento.

César González-Ruano aseguraba que para hacer una entrevista en la que sólo hubiese preguntas y respuestas no necesitaba estar delante del personaje, le bastaba con "enviar al botones" (o enviar el cuestionario, podríamos decir... para no entrar en cuestiones profesionales).

Sólo hay una fórmula para el éxito: la experiencia, aprender de los errores y aplicar las mayores dosis de sentido común y naturalidad. De forma que el entrevistado no sienta en ningún momento que se le somete a un tercer grado, a un interrogatorio severo, puesto que será el camino más seguro para que se cierre en banda y apenas cuente nada de interés. Finalmente, insistamos en que eso no significa que el periodista no pueda o deba realizar preguntas comprometidas, algo que nunca interesará estratégicamente hacer al inicio de la entrevista, sino hacia la mitad o final del tiempo concedido para su puesta en práctica.

\section{La entrevista como género}

Al tratar sobre la entrevista, y la realidad periodística y literaria, resulta recomendable acercarse a obras como las siguientes: Acosta, J. (1973) Periodismo y literatura; Arfuch, L. (1995). La entrevista, una invención dialógica; Balsebre y otros (1998). La entrevista en radio, televisión y prensa; Cantavella, J. (1996). Manual de la entrevista periodística o Quesada, M. (1984). La entrevista: obra creativa, entre otras publicaciones igualmente de interés.

No han sido pocos los autores que han considerado la entrevista como una modalidad del reportaje. Sin embargo, en la actualidad, y en la línea de lo que defiende Juan Cantavella (1996), dicha adscripción no tiene sentido. La entrevista constituye un género informativo con plena autonomía dentro de la producción textual y discursiva de la prensa, tanto española como internacional.

Este autor concreta en tres sus argumentos: "Primero: la entrevista ha llegado a un desarrollo conceptual y práctico que no tenía en el pasado. Su fuerza y presencia están muy por encima de las que ostentaba en décadas anteriores, por lo 
que es justo dotarla también de una posición conceptual que la ponga en pie de igualdad con otros géneros que se cultivan con la misma atención.

Segundo: quizá en el pasado se apreciara su dependencia del reportaje, pero no en nuestros días. Los lectores pueden establecer la relación que existe entre la columna y el comentario respecto del artículo, por ejemplo, pero difícilmente alcanzan a ver que la entrevista es una de las especies del reportaje. Una columna puede ser designada con el nombre de artículo, pero ¿alguien llamará reportaje a una entrevista?

Tercero: en un primer momento la entrevista fue contemplada como un texto uniforme, pero su desarrollo ha sido tal a lo largo de este siglo que apreciamos la existencia de varias clases y hasta derivaciones, como la encuesta. La complejidad de esta clase de textos dialogales merece que la desliguemos del reportaje para darle atención particular" (Cantavella, 1996: 33-34).

Siguiendo al mismo autor, podemos hablar de dos grandes tipos de entrevista:

1. Entrevista de declaraciones

2. Entrevista de semblanza o de personalidad

Considera este experto entrevistador que "la que podríamos denominar como entrevista de batalla en el periodismo es la de declaraciones. Es la más frecuente, la más sencilla, la más breve y fácil de leer por su inmediatez, dinamismo y acercamiento a los hechos que conforman la actualidad. La de personalidad tiene un peso específico y una solidez que no permite que haya más de una o dos por número, mientras que ésta se halla dotada de ligereza y versatilidad. Unas veces contiene una noticia en sí misma; otras, explica, amplía o redondea la noticia -con un testigo o un experto en la materia- y entonces se coloca a continuación de aquella o se ofrece en días sucesivos. Aunque pensamos que la entrevista de declaraciones cubre un espacio homogéneo que no es indispensable trocear con subdivisiones, algunos autores descienden a matizar que en su seno coexisten dos apartados: la que se refiere a hechos y la que se explaya en cuestiones de opinión, lo que sin duda ocurre, aunque sea difícil de discernir. Efectivamente se dan unos matices de diferenciación que pueden ser resaltados, porque no es lo mismo informar sobre un suceso que comentar una situación o una tendencia. Lo que no vemos tan claro es que a la primera se la denomine de noticia: todas provienen de lo mismo, porque tan noticia es el dramático accidente de un autobús como la bajada de tipos de interés o la actualidad del pensamiento de Zubiri” (Cantavella, 1996: 40-41). 


\section{Variantes del género: del cuestionario cerrado a la entrevista en profundidad.}

La entrevista constituye un género periodístico que admite cierta variedad en su tratamiento y enfoque. Precisamente en función de la modalidad de entrevista que se quiera realizar habrá que cuidar especialmente algunos aspectos relacionados con la planificación y labor previa de documentación, así como respecto al tipo y número de preguntas, la introducción o entradilla al cuerpo del texto de la entrevista que se vaya a publicar, etcétera.

Dos son las posibilidades de plasmación literaria del contenido de la entrevista llevada a cabo: la fórmula pregunta-respuesta o la exposición mediante citas literales de los testimonios del entrevistado alternadas con el estilo indirecto (la exposición por parte del redactor sin necesidad de usar comillas, naturalmente siendo fiel a lo dicho por el personaje, sin sacar de contexto sus afirmaciones, aunque la literalidad no sea totalmente exacta). Algunos autores han denominado a esta última opción "reportaje de citas", por poder presentar algún parentesco con aquel género, en la medida en que permite un tratamiento más creativo y próximo a los reportajes convencionales, en los cuales precisamente las declaraciones de los protagonistas informativos obtenidos mediante entrevista o por otras vías devienen pieza clave en la calidad literaria y periodística de los mismos; amén de la habilidad del periodista para escribir, desde luego.

La mezcla de ambas fórmulas o estilos aparece en ocasiones en la prensa, si bien su empleo supone un cierto riesgo para los periodistas menos expertos, por lo que resulta aconsejable optar por una de las dos. Además, conviene hacerlo así para no generar demasiada confusión en el lector o ser demasiado pretencioso en la escritura si no se cuenta con una especialización como entrevistador y si no se tienen suficientes garantías a la hora de afrontar el cometido.

En este sentido, lo mejor para las primeras etapas de ejercicio profesional suele ser ajustarse lo más posible a las reglas y las tradiciones, para, en su caso, una vez dominado lo clásico atreverse a innovar con los géneros y su tratamiento, siempre dentro de un orden y sabiendo que un periodista que no tenga todavía una firma especialmente reconocida debe ser muy cauto, extremadamente prudente, en primer lugar por el propio interés de su carrera personal, pero también por otras consideraciones varias en las que no podemos detenernos aquí.

Repasando lo que exponen los principales autores y entrevistadores, se puede hacer la siguiente enumeración de tipos de entrevistas, agrupando las modalidades que presentan bastante parecido y al margen de que lo más habitual sea la mezcla de dos o más variedades. No nos pararemos a entrar en los matices y peculiaridades de cada tipo, si bien hay que mencionar que todas ellas pueden abarcar desde el cuestionario cerrado hasta la entrevista en profundidad que va creciendo conforme se realiza: 
- Entrevista de semblanza, de personalidad o de perfil biográfico y profesional.

- Entrevista de declaraciones.

- Entrevista de investigación (en primer plano la de naturaleza periodística, pero también la historiográfica, científica, etcétera).

- Entrevistas de opinión pública, mediante encuestas y otras fórmulas.

- Entrevista periodística fingida (poco habitual)

- Otros tipos: el llamado cuestionario Marcel Proust, denominación que viene de haber sido este escritor el primer personaje al que se le propuso someterse a ella. Se trata de una amplia batería de preguntas cortas para las que se exige una respuesta también breve. Casi siempre consiste en interpelaciones de carácter personal o sentimental, y con frecuencia se repiten cuestiones (por ejemplo, se hacen preguntas de esta índole: “¿cuál es el rasgo esencial de su carácter?"; “¿Qué cualidad valora más en una persona?"; “¿Qué personaje histórico admira más?”; y así hasta veinte, treinta o un mayor número de preguntas).

Por su parte, otra autoridad en la investigación académica sobre el género de la entrevista periodística como es Montserrat Quesada considera a grandes rasgos la existencia de las siguientes clases (Quesada, 1984):

- Entrevista informativa: la más frecuente, hasta llegar al abuso clarísimo por parte de los medios y de las fuentes. Se corresponde con la entrevista para recoger declaraciones. Investigaciones recientes confirman que más del $70 \%$ de lo publicado por la prensa son declaraciones obtenidas mediante entrevistas, ya sean exclusivas o, por lo general, de acceso abierto (comunicados o teletipos de agencias, ruedas de prensa y otras convocatorias a los medios), informales o formales. La práctica del "periodismo de declaraciones" se inicia en España durante la Transición a la Democracia y permanece como un mal debido a su exceso. Frente a él, se debería intentar conocer la opinión de otros protagonistas distinto a los de siempre, y con declaraciones que no sean las que tienen todos los medios, realizar más investigación para obtener noticias propias y demás.

- Subtipo: entrevista de indagación (para esta autora no es sólo la entrevista característica del llamado Periodismo de Investigación, sino que va más allá al corresponder a la entrevista final que se ve obligado a hacer un periodista al implicado en un asunto relevante investigado previamente).

- Entrevista literaria o creativa: está reservada a las grandes plumas del periódico o a escritores y otros colaboradores externos. Su ubicación natural y habitual es la de los suplementos y revistas dominicales, junto con la presencia en secciones de Cultura. En su éxito influyen las dotes personales de quien la realiza y especialmente el domino indiscutible de la palabra escrita, pero también el interés o la profundidad del tema o la personalidad del interpelado. Es por lo general más intemporal y está parcial o totalmente alejada de la batalla diaria (política, económica, social...), lo que la diferencia de forma considerable de la entrevista informativa y permite un margen mayor al autor para mostrar su competencia, entre otros, en el ámbito de la redacción y la escritura periodísticas. 


\section{BIBLIOGRAFÍA}

ACOSTA MONTORO, J. Periodismo y literatura. Guadarrama, 2 vols., Madrid, 1973. ARFUCH, L. La entrevista, una invención dialógica. Paidós Papeles de Comunicación, Barcelona, 1995.

BALSEBRE, A., MATEU, M. y VIDAL, D. La entrevista en radio, televisión y prensa. Cátedra, Madrid, 1998.

CANTAVELLA, J. Manual de la entrevista periodística. Ariel Comunicación, Barcelona, 1996.

QUESADA, M. La entrevista: obra creativa. Mitre, Barcelona, 1984. 